\title{
Being Ethnographic: A Guide to the Theory ANd Practice of EthNOGRAPHY
}

Raymond Madden (London: Sage, 2010, 196pp.)

\section{(paperback)}

\section{Review by Jodie Taylor, Griffith University}

The differences among groups of people and their life-worlds, the extraordinariness of these differences and increasingly, the mundanities of everyday lives have, for some time, been of interest to those who study the human subject. No longer a guarded secret in the anthropologist's toolkit, ethnography is now a method widely employed by scholars across a range of humanities and social science disciplines, and Being Ethnographic is a useful new addition to the existing corpus of methodological 'how to' texts, providing practical, experiential and theoretically sound advice on how one may interdependently 'do' and 'think about' ethnography to thus, 'be ethnographic'.

Madden presents his book in four thematic sections, offering the reader a critical and comprehensive overview of the ethnographic process, from the point of definition to the final stages of writing up. Section One, 'Key Concepts and Theoretical Frames', establishes some basic and necessarily flexible, definitions and structures, broadly mapping the ideas and techniques that have shaped ethnographic practices. Here, the author offers advice that will prove particularly useful to the novice ethnographer on balancing emic and etic understandings of human behaviour, ethical considerations, epistemological differences between anthropological and sociological ethnographies and field settings. Contextualised in his own experiences in the field, Madden also presents the reader with sound guidance on conceptualising the geographical, social and emotional multiplicities of the field.

In Section Two, 'Doing Ethnography', Madden outlines the initial steps towards gaining access to subject, unpacks the intricacies of ethnographic conversations and interviews, explores field relationships and examines the ethnographic gaze. Madden, an Australian anthropologist, begins the book on a particularly strong note by introducing himself to his reader and continues, in this section, to highlight the importance of critiquing one's ethnographic gaze and establishing methodological reflexivity, interrogating the author's positionality and subsequent influence on the text. Building on his experiences as a 'Whitefella' working in Australian Aboriginal communities, he presents the budding ethnographer with wise instruction on identifying and negotiating power relations and social positioning. However, he fails to engage in any satisfying way with work on autobiographical methods and autoethnography, as there are obvious connections that could have be made here. In addition, this section of the book may also have benefited in parts from a more detailed discussion of feminist ethnographies. Particular features of this section worth signaling include Madden's plain-spoken and practical guidance on conducting interviews and making observations, and his methodological and theoretical discussion of both the potential and the limitations of visual ethnography.

Section Three, which the author calls 'Inscription', deals in three chapters with the processes of writing 'down', writing 'out' and writing 'up'. Here, Madden systematically unpacks some of the strategies of writing down, visually and audibly recording field data through examining the variety of purposes served by ethnographic note-taking. Acquisition of the raw data is followed by analysis and interpretation or writing 'out'. This chapter features a useful section on analysis and interpretation based upon the author's doctoral experiences that practically illustrate some of the quandaries an ethnographer will almost certainly encounter when attempting to 'distil' their data. In the final chapter to this section, Madden attempts to de-mystify the writing 'up' process. While he successfully breaks down the construction of ethnographic 'storied realities' into a logical four-step process, his descriptions of ethnographic writing styles is not as thoroughly explored, ultimately 
leaving the reader with less of an idea of the 'how to', 'when' and 'why' an ethnographer should consider the use of particular styles and voices.

Madden's book does not shy away from traversing ethnography's critical frontiers. As such, a key strength of the text lies in its dealings with cyber-ethnography and the ethnography of humananimal relations in the final section of this book, 'Expanding Ethnography'. Madden establishes the argument that cyber-ethnography can be done using the same set of ethnographic tools as any other field setting because a subject's virtual sociality ensues 'real' emotions. As such, he cautions against any real/virtual distinctions to be made between these worlds on the basis of authenticity and/or fakeness. According to Madden, what will push the boundaries of ethnographic methods more than any other researcher-subject relationship or context is the limits of human-animal intersubjectivity. This said: Madden does not shy away for this, encouraging exploration of the human-animal nexus on the basis that these relationships significantly shape human lives.

This book is sure to be a helpful resource to advanced undergraduates, postgraduates and career researchers who seek a clearly defined and logically structured text which successfully contextualises ethnographic theory in the real-world field experiences of the book's author. In particular, the set of questions, discussion topics and further suggested readings that Madden provides at the end or each chapter make this text both a useful course work tool and a comprehensive resource for self-directed learning. Not only does Madden unpack for his readers the 'how to' and 'what for' of the entire ethnographic process, but importantly, he has also taken the vital step of offering his readers critical insights into, and guidance on, the interpersonal, emotional and embodied dimensions of working with people in ethnographic settings. 